\title{
EDUCACIÓN, MAESTROS EN TIEMPOS RECIENTES. TRES INVESTIGACIONES
}

\author{
José G. Viloria Asención ${ }^{1}$ \\ Universidad Nacional Experimental Simón Rodríguez \\ Grupo de Investigación HISULA \\ viloriajg@gmail.com
}

Recepción: 18/04/2010

Evaluación: 15/06/2010

Aceptación: 12/11/2010

Artículo de Revisión

\section{RESUMEN}

El conjunto de reflexiones que se presentan, responden a los esfuerzos realizados durante el desarrollo de tres Investigaciones sobre la Educación, la Pedagogía y sus prácticas, durante la última mitad del siglo XX e inicios del siglo XXI. Las Investigaciones se asumieron desde un enfoque fenomenológicointerpretativo, lo que permitió otorgar la palabra a los testigos presenciales e informantes de primera fuente sobre el asunto en estudio. Los métodos empleados fueron la Entrevista en Profundidad, la Historia de Vida, la Historia Oral y los Relatos. El sentido histórico que se logró en las investigaciones invita a re-pensar el desarrollo de la Educación en los tiempos por venir.

Palabras clave: Investigación, Fenomenología, Testigo, Educación, Pedagogía, Política

\footnotetext{
1 Profesor de Educación Física. Doctor Ciencias de la Educación. Coordinador de la Línea de Investigación Estudios Políticos y Sociales en Educación, UNESR Los Teques. Coordinador Académico Línea de Investigación Dinámicas Psico-Sociales y Ambientes de Aprendizaje, UNESR Post Grado Caracas. Miembro de Línea de Investigación Laboratorio Socio Educativo, Instituto Pedagógico de Caracas. Coordinador de Investigación Centro de Estudios Superiores e Investigación Deportiva, Comité Olímpico Venezolano.
} 


\title{
EDUCATION, TEACHERS IN RECENT TIMES. THREE RESEARCHES
}

\author{
José G. Viloria Asención ${ }^{1}$ \\ Universidad Nacional Experimental Simón Rodríguez. \\ HISULA Reserach Group \\ viloriajg@gmail.com
}

\begin{abstract}
The set of reflections here presented answer to the efforts did during the development of three Education researches, Pedagogy and its practices during the last half-century and early twenty-first century. Researches were undertaken from an interpretive phenomenological approach, allowing to provide witnesses and informants of the first source on the subject under study. The methods used were interviews, Life History, Oral History and Stories. The historical sense was achieved in the research invited to think once again the development of Education in the times to come.
\end{abstract}

Key words: Research, Phenomenology, Witness, Education, Pedagogy, Politics 


\section{INTRODUCCIÓN}

La Educación es una práctica social que no es posible contenerla en el tiempo. Ella trasciende épocas, espacios geográficos, acciones, estrategias y hasta a ella misma, una interrogante que sobre su existencia se plantea permanentemente el hombre, tiene que ver con lo siguiente, ¿ella es creación del hombre? o ¿el hombre es lo que es gracias a ella?

Lo cierto de todo esto es que ella -la Educación- es posible desde la interrelación entre los seres humanos, es un proceso generador de transformaciones que es posible gracias al producto alcanzado, el aprendizaje. Hablar de y sobre la Educación, implica atender los hechos históricos vividos por el hombre y los procesos de transformación que ha logrado, la Educación ha sido protagonista de primer orden en la vida de la humanidad. Bien desarrollándose desde el viaje y traslado de la información de una generación a otra a través de las tradiciones y las costumbres, o mediante el Sistema Escolarizado que forma y prepara al colectivo para la vida ciudadana.

En estos escenarios la figura y quehacer del Maestro ha resultado de significación para cada colectivo, que alcanza hasta la valoración que cada País ofrece a estos héroes, que en su mayoría resultan anónimos, y en consecuencia el reconocimiento se hace a la legión de ellos por lo que hicieron. Este anonimato cada vez se hace más fuerte, probablemente se deba al hecho de que cada generación es más numerosa y las tecnologías, la innovación no facilitan hacerlos visibles en los logros transformacionales que promueve la Educación.

Las reflexiones que se ofrecen seguidamente atienden a tres investigaciones realizadas entre 1996 y 2009, en las que el asunto de interés lo tiene la Educación. Se estudió en cada una de ellas, las diferentes prácticas que la hacen posible, así vemos que la Primera Investigación se tradujo en la Tesis de Maestría que lleva por título: "formación de jóvenes bajo el carisma de los salesianos. Un estudio de caso, desde un enfoque etnográfico."2 La Segunda permitió la elaboración de la Tesis Doctoral y lleva por título "La educación y la escuela en Venezuela. Desde el relato y la mirada de un testigo presencial. Gilberto Picón Medina. Una historia de vida." ${ }^{3}$ Y la Tercera fue el desarrollo del Proyecto presentado

\footnotetext{
2 VILORIA, José. (2002): Formación de Jóvenes Bajo el Carisma de los Salesianos. Un Estudio de Caso, desde un Enfoque Etnográfico. Trabajo de Grado de Maestría no publicado. Universidad Nacional Experimental Simón Rodríguez, p. 87.

3 VILORIA A., José. (2007): La educación y la escuela en Venezuela a partir de la experiencia de Gilberto Picón Medina: Una Historia de Vida. Venezuela Fondo Editorial de la Universidad Pedagógica Experimental Libertador. FEDEUPEL, p. 56.
} 
como estudio Post Doctoral y se titula "La Pedagogía Social en el escenario de la Educación Social. Un momento para múltiples miradas.”4

De alguna manera las tres investigaciones están unidas por el nudo temático que significa la Educación. Es necesario precisar que las tres Investigaciones se desarrollaron desde un enfoque fenomenológico-interpretativo, donde la Entrevista en Profundidad, los Relatos, las Historias de Vida, las Historias Orales y la Revisión de Documentos Personales nutrieron el esfuerzo investigativo ${ }^{5}$. Párrafos supra señalé que hablar de Educación era hablar del hombre, y en estas investigaciones se dio la palabra a voces anónimas para escuchar desde las primeras fuentes cómo se vive la Educación, cómo se practica, qué significa y qué hemos hecho por hacerla cada vez mejor. ${ }^{6}$

Testimonios de quienes han vivido la Educación en contextos diferentes, ofrecen desde sus experiencias las coincidencias de la vida de los hombres en el desarrollo y evolución de la Educación, que como factores comunes tienen a Venezuela, la Escuela, la Comunidad, Niñas y Niños, Maestras y Maestros, Representantes y las que iremos descubriendo en el avance de estas reflexiones.

Seguidamente iniciaremos los comentarios y reflexiones sobre cada Investigación, luego para finalizar interpretaremos las coincidencias y elementos diferentes de cada una, y así ofrecer una reflexión final sobre las mismas y aproximar una interpretación sobre la Educación y sus prácticas.

\section{1. formación de jóvenes bajo el carisma de los salesianos. Un estudio de caso, desde un enfoque etnográfico ${ }^{7}$}

Esta Investigación se inició desde la cotidianidad laboral que desempeñaba

\footnotetext{
4 VILORIA A., José. (2009): La Pedagogía Social en el escenario de la Educación Social. Un momento para múltiples miradas. Informe Final del PROYECTO DE INVESTIGACIÓN S107-002 UNESR-CDCHT. No publicado. Caracas, Venezuela.

5 La revisión bibliográfica que acompañó este desarrollo Metodológico fue orientada desde: RICOUER, P. (2004): La Memoria, La Historia, El Olvido, Buenos Aires, Editorial Fondo de Cultura Económica.

RICOUER, P. (2002): Del Texto a la Acción. Ensayos de Hermenéutica II., México, Editorial Fondo de Cultura Económica.; RICOUER, P. (1999): Historia y Narratividad, Barcelona, Ediciones Paidós. España; RICOUER, P. (1997): La Función Hermenéutica del Distanciamiento; [Comp.] DOMÍNGUEZ C., J (1997): Hermenéutica, Madrid, España, Editorial ARCO/LIBROS, SL., pp.115-133.

6 Este aspecto se trabajó desde lo propuesto por: BOLÍVAR, Domingo y Fernández. (2001): La Investigación Biográfica Narrativa en Educación. Enfoque y Metodología, Madrid, España, Editorial La Muralla, S.A., CÓRDOVA, V. (1993): Historias de Vida. Una metodología alternativa para Ciencias Sociales, Caracas, Venezuela, Fondo Editorial Tropikos, p. 87.

7 Viloria, José. (2002): Formación de Jóvenes Bajo el Carisma de los Salesianos. Un Estudio de Caso, desde un Enfoque Etnográfico. Trabajo de Grado de Maestría no publicado. Universidad Nacional Experimental Simón Rodríguez.
} 
para ese entonces (1996), Facilitador-Investigador de la Universidad Nacional Experimental Simón Rodríguez (UNESR), de los Cursos Prácticas Profesionales y Proyecto I. Propicié un espacio de encuentro que hizo posible que los participantes desde una realidad pudieran construir su proceso de aprendizaje en lo concerniente a las Prácticas Profesionales, y a su vez el mismo pudiera ser problematizado y desarrollar la configuración de una Investigación cubriendo las exigencias académicas de los cursos Proyecto I y II. Para construir lo que se transformaría en el Trabajo Especial de Grado a nivel de Pre Grado, y a su vez resultarían ser el nutriente básico de mi Investigación que culminó como Trabajo Especial de Grado de la Maestría que cursaba para ese entonces.

El asunto central que fundamentó el desarrollo de ésta investigación se focalizó en estudiar cómo los Salesianos, desde una congregación religiosa, lograban desarrollar un proceso educativo escolarizado o no que según señala Viloria,${ }^{8}$ tiene como razón ...el legítimo propósito de la educación es contribuir a lograr que cada sujeto sea individuo y colectivo, desarrollando al máximo su potencialidad como ser humano, es decir, que la relación entre los hombres a través del saber contribuya al crecimiento, desarrollo y fortalecimiento de la humanidad en armonía con el entorno que le rodea y le permita compartir la existencia en estos tiempos y otros, los anteriores y los futuros.

Desde la llegada de los europeos a tierras de éste continente, la Educación y la Religión han estado unidas por bien o por mal en el desarrollo y evolución de la Educación y los colectivos humanos. Con sus contradicciones y aciertos, con sus virtudes y miserias. En atención a esto Viloria, ${ }^{9}$ precisa que, El punto de interés del presente estudio, son los jóvenes egresados de los institutos educativos religiosos salesianos y la relación existente entre los procesos educativos y los ideales en la formación ideológica evangelizadoras en sentido integrado y complementario, que de alguna manera garantizan el éxito de sus esfuerzos en la formación de la juventud desde los postulados filosóficos y religiosos.

Para lograr satisfacer las inquietudes que dieron origen a la investigación se formularon las siguientes pretensiones como objetivos orientadores,

\section{Lo que se pretende conocer}

\section{La Gran Tarea}

- Estudiar el proceso de formación integral de jóvenes bajo la Doctrina

8 Ibídem., p. 6

9 Ibídem., pp. 7-9

Rev. hist. edu. latinoam. Vol. 15. Año 2010, pp. 299 - 322 
Salesiana y su relación con la comunidad. Liceo San José de Los Teques. Estado Miranda.

\section{Las Acciones Específicas}

- Analizar los postulados de la Doctrina Salesiana en el proceso de educación, formación y desarrollo de jóvenes.

- Identificar las fases que orientan el proceso de formación y desarrollo de jóvenes, bajo el contexto de la doctrina salesiana.

- Describir las acciones y significados que generan el quehacer de los jóvenes en su integración a las comunidades.

- Conocer las expectativas, valores y necesidades de los jóvenes durante el proceso de su formación.

Desarrollar la investigación implicó una tarea interesante, ya que fue importante lograr un diseño que hiciera posible conocer de primera fuente (los actores sociales de la situación que se estudió), la información que se trabajó para lograr interpretar y comprender cómo los Salesianos desarrollan su manera/ modo de vivir la Educación. De igual forma el arqueo bibliográfico se condujo hacia lo cobertura no sólo de la información teórica relacionada con la Educación, la Religión y la Formación, sino que se amplió hacia los terrenos de las discusiones teológicas y filosóficas que atienden desde la religión cristiana; revisando documentos vitales como: concilio Vaticano, ${ }^{10}$ (1965). Conferencia general del episcopado latinoamericano. ${ }^{11}$ (1986). consejo general de la sociedad salesiana, ${ }^{12}$ (1990). Lo que favoreció significativamente la Investigación.

En cuanto al diseño metodológico para el desarrollo de la vivencia investigativa, éste se configuró en torno a un enfoque fenomenológicointerpretativo, desde una práctica etnográfica soportada en la administración de una serie de Entrevistas en Profundidad, la Observación Participante y la Revisión de Documentos.

La selección de la Muestra fue Intencionada, es decir, atendió a las consideraciones expuestas por Viloria. ${ }^{13}$ “... la muestra no es de tipo rígida, ni

\footnotetext{
${ }^{10}$ CONCILIO VÁTICANO II, (1965). Constituciones. Decretos. Declaraciones. España. Ediciones Paulinas.

${ }^{11}$ CONFERENCIA GENERAL DEL EPISCOPADO LATINOAMERICANO. (1986): Medellín, Conclusiones. Colección IGLESIA EN ACCIÓN Nº 1. Lima. Perú. Ediciones Paulina.

${ }^{12}$ CONSEJO GENERAL DE LA SOCIEDAD SALESIANA,(1990): XXIII Capítulo

General SALESIANO: Educar a los Jóvenes en la Fe. Madrid. Ediciones CCS.

13 Ibídem., pp. 41- 41-42.
} 
establecida previamente, ya que el investigador tiene la potestad de ir buscando informantes significativos a medida que se realiza la investigación." Ya que ésta permite "... obtener representatividad de los contextos, individuos o eventos, lograr heterogeneidad del caso en estudio seleccionado, escoger casos que teóricamente son significativos." Un complemento de valor que ofrece el citado autor, tiene que ver con:

La muestra intencional en la investigación cualitativa posee las siguientes características:

- Es emergente porque la muestra no se extrae previamente, sino que se va conformando a medida que se lleva a cabo la investigación. De una entrevista puede surgir un nuevo informante de significativo valor para la investigación.

- La selección de las unidades de información es serial, por cuanto para cumplir con el requisito de máxima variación, cada unidad se relacionará después de analizar las respuestas de la unidad anterior, de manera tal, que permita la búsqueda de nuevos datos.

- La muestra es ajustada continuamente, de acuerdo a los temas van surgiendo.

- El muestreo culmina con la redundancia en el momento en aparecen datos repetidos.

La Muestra para el desarrollo del proceso de recolección de la información quedó constituida como indica Viloria. ${ }^{14}$ La muestra definitiva quedó constituida de manera inicial por tres miembros de la Comunidad del Liceo San José de los Teques y dos representantes, ellos son, dos jóvenes (responsables de grupo), un sacerdote quien es responsable del proceso, los representantes una docente en una Institución gubernamental y una abogado. Los jóvenes y el sacerdote fueron objeto de la Entrevista en Profundidad, las representantes atendieron a una Entrevista de Grupo. Los mismos, resultaron seleccionados de manera intencionada, teniendo como criterio su responsabilidad en el proceso de formación de los jóvenes, los representantes por esa responsabilidad directa con sus hijos.

Los hallazgos suministraron elementos importantes para interpretar y comprender el Proceso de Formación de Jóvenes Bajo el Carisma de los Salesianos. Los mismos brindan la posibilidad de una visión multidimensional del hecho y acto educativo que viven y desarrollan, señala Viloria, ${ }^{15}$ Lo que se ha logrado a lo largo de este trabajo investigativo, se puede ofrecer sobre las

\footnotetext{
14 Ibídem., p. 42.

${ }^{15}$ Ibídem., pp. 116- 117-118.
} 
premisas de cuatro escenarios en el ámbito educativo y formativo, el primero el proceso de aprender bajo el carisma de los salesianos (identificado así por los propios religiosos y jóvenes), el segundo el ejercicio de la docencia, la identidad de los proyectos comunes y por último la investigación como práctica para la búsqueda de respuestas. Y seguidamente lo que se interpretó en cada espacio: "El primer escenario se refiere al proceso de aprender bajo el carisma de los salesianos, en donde los elementos que lo emblematizan, son la comunicación, el afecto, la identidad con el proceso y la transformación de los sujetos como producto." Luego.

El ejercicio de la docencia ha sido entendido por los modelos educativos tradicionales, como la responsabilidad de una individualidad que se ha formado para desarrollar experiencias educativas, sin embargo, la dinámica social y educativa de hoy, reclama la participación y responsabilidad de todos en el desarrollo del proceso educativo en todas sus dimensiones, lo que hace posible que el ejercicio de la docencia sea responsabilidad de quienes participan del proceso educativo, haciendo de ella, un ejercicio compartido entre quienes tienen la necesidad de aprender y de quien está preparado para facilitar que dicho proceso se desarrolle.

Las dimensiones que siguen concretan el vivir la Educación desde el Carisma de Los Salesianos, quienes ya tienen más de un Siglo en Venezuela y sus aportes demandan ser socializados, compartidos y vividos colectivamente en procura de un fin común, el bienestar de la sociedad. Las dimensiones restantes indican que, La identidad con los proyectos, es lo que determina y define los criterios sobre los cuales establecen acuerdos los docentes, los representantes, los padres, los religiosos y los alumnos; para elaborarlos y que permiten conducir el proceso de formación, hacia el horizonte que este grupo humano precise. Resultando digno de señalar, que esta identidad no es exclusividad de religión alguna, lo que si debe asumirse como exclusividad, es el producto que resulte de esa unidad de criterios que fortalecen los proyectos que se planteen y propongan, para que en su esencia redunde en beneficios para los jóvenes y en consecuencia la comunidad donde se desarrollan.

La investigación ha de ser vista y entendida, como el aprendizaje que permanentemente ha de lograrse para obtener las respuestas en atención al desarrollo de los procesos educativos y en los que esté involucrado el hombre, respondiendo a la satisfacción de las necesidades de cada sujeto en su individualidad y como miembro de grupo. ${ }^{16}$

\footnotetext{
${ }^{16}$ Ibídem., p. 118
} 
José G. Viloria Asención

La investigación culmina con una afirmación construida desde los hallazgos, logros, interpretación y comprensión del estudio, la misma indica:

... las instituciones escolares, religiosas o no, han de ser valoradas como el espacio que amplía y da prosecución al desarrollo de los procesos de aprender de los hombres, complementando lo que el hombre y la sociedad toda, ha de aprender para convivir en la construcción de los escenarios que nos permitan un mejor vivir. De igual manera, que la educación y todos los procesos de interrelación que la fortalezcan deben ser responsabilidad de todos los miembros del colectivo. ${ }^{17}$

La investigación ofrece una visión de los movimientos que durante el pasado siglo y lo que va del presente, la Educación y la Religión han caminado unidas de la mano en el proceso de desarrollo social desde las vivencias educativas. Así mismo invita a considerar de manera firme que la Educación es una responsabilidad de todos, y que la exclusividad de ella al desempeño del Maestro es una discusión agotada.

\section{La educación y la escuela en Venezuela. Desde el relato y la mirada de un testigo presencial. Gilberto Picón Medina. Una historia de vida ${ }^{18}$}

Los estudios Doctorales demandan de los Doctorandos la realización y desarrollo de una investigación que se caracterice por lo inédito, original, los aportes de tipo académico e investigativo que dicho esfuerzo haga posible, de tal manera que las Tesis Doctorales son elaboraciones intelectuales de alto nivel y además ofrecen una nueva y diferente "teoría" sobre el asunto que dicha investigación estudió.

La síntesis reflexiva que se presenta seguidamente, responde a una investigación que se vivió como el tránsito hacia la elaboración de la Tesis Doctoral que desarrollé como exigencia académica, para optar al título de Doctor en Ciencias de la Educación en la Universidad Nacional Experimental Simón Rodríguez, Venezuela. Más sin embargo, durante el andar de la vivencia logré superar el dilema de todo proceso educativo, la evaluación de los aprendizajes. Poder percibir los cambios conducentes a la transformación que implican la madurez lograda como aprendizaje, fortalecieron la certeza de no esperar por la aprobación de otros como ajenos al proceso.

\footnotetext{
${ }^{17}$ Ibídem., p. 118

18 Viloria Asención, José. (2007): La educación y la escuela en Venezuela a partir de la experiencia de Gilberto Picón Medina: Una Historia de Vida, Caracas, Venezuela, Fondo Editorial de la Universidad Pedagógica Experimental Libertador. FEDEUPEL, p. 56.
} 
La evaluación constituyó el escenario donde el compartir los logros alcanzados, sirvió de arquitectura para la construcción de los aprendizajes. Evidentemente se trató de una evaluación constructiva en la que los elementos nuevos, diferentes y particulares valoraron lo subjetivo e intersubjetivo que significó compartir una investigación cargada de didáctica, pedagogía y sobre todo de curiosidad rigurosamente dirigida. Y queda expreso cuando Viloria ${ }^{19}$ señala que, “...el hombre es el protagonista de lo que ocurra y tal situación es asunto que atañe a todos quienes estén involucrados en el hecho." Es vital precisar que ello fue posible porque se desarrolló la investigación desde un enfoque fenomenológico-interpretativo.

De igual manera la vivencia resultó ser un permanente aprendizaje, ello fue posible por las características de la investigación, el enfoque desde el cual se asumió y los métodos que se administraron. En este sentido Viloria ${ }^{20}$ indicó que, Cuando desarrollamos un trabajo de indagación, desde el cual buscamos nuevos conocimientos, reafirmar los existentes o aclarar algunas dudas sobre lo que revisamos lo llamamos investigación. Dicho proceso es una manera de relacionarnos con los demás, por coincidir o discrepar desde lo que buscamos, cómo lo hacemos y discutimos sobre ello. Este acto humano ha trascendido el mero hecho de la búsqueda, ya que su valor está identificado inclusive, con modos de vivir.

Ello permite afirmar que desarrollar una investigación debe entenderse como la vía para alcanzar una manera/forma de vivir esos momentos que demandan nuestro esfuerzo y tiempo. Precisando que, "Es por ello que este trabajo es académico y se hace científico o viceversa, pero nunca deja de ser un acto humano." Argumentando además, que ese producto intelectual cobra vida, ofreciendo los cambios y transformaciones que lo hace sentir diferente a lo que convencionalmente se conoce como trabajos de investigación. Al respecto dice:

El documento que sigue después de este escrito, recoge lo que inicialmente comenzó como un ejercicio académico, que pretende ser científico, pero que por sus características ha logrado adquirir vida. Ya que desde él se tiene por propósito, realizar un recorrido por la historia de la Educación y la Escuela venezolana -luego de la muerte de Juan Vicente Gómez-, con la finalidad de conocer cómo la vivió un venezolano que estuvo presente en muchos de estos escenarios. Para desde esta experiencia, lograr una diferente mirada sobre lo ocurrido. ${ }^{21}$

\footnotetext{
19 Ibídem., p.14.

${ }^{20}$ Ibídem., pp. 15-16.

${ }^{21}$ Ibídem., pp. 16-17-18.
} 
Tal significación logró esta vivencia, que en todas sus dimensionas el autor valora lo vivo del proceso/producto, hasta presentar una configuración de estructura distinta a la tradicional, señalando; Lograr construir el camino por donde transitó esta vivencia, la cual reitero que es atractiva, me hace pensar en el producto del esfuerzo como un ser que tiene vida, no sé si propia, pero tiene vida, está vivo. Confieso que no me agrada hablar de él como una exigencia académica, siento que tiene vida, que cuenta con un corazón que late y una mirada de búsqueda permanente. Lo vi crecer y desarrollarse, que se hizo independiente, es decir, él me dijo cuál era el camino a seguir, y hasta cómo caminar. Es una vivencia que me hace vivir algo nuevo constantemente.

En cuanto a la estructura que integró el documento final indicó; La vivencia exigió hacerse sentir diferente a lo convencional, por ello las secciones que integran el documento son tituladas como Actos. En virtud de tratarse de cómo vivió y durante ese tiempo cómo se desarrolló la Escuela y la Educación, se ofrece una salida a escena de quienes actuaron durante ese ínterin a través de los relatos de los informantes y testigos de tales eventos.

Durante el desarrollo de la investigación fue preciso revisar y argumentar las diversas concepciones sobre la Historia como saber humano, ya que ésta trató sobre la Historia de Vida de un Testigo Presencial y significativo para conocer la Historia reciente de la Escuela y la Educación en Venezuela, por ello Viloria $^{22}$, indicó La conciencia histórica de la sociedad responde a la participación protagónica de quienes intervienen en los hechos, pero además define las características colectivas e individuales de los actores, sus intereses, comportamientos, intenciones, pensamientos y la especulación sobre sus aspiraciones. Se entiende así que la historia, tiene como objeto de estudio no sólo los hechos y sucesos ocurridos donde está presente el hombre, y se ha transformado la sociedad, sino que además debe indagar en detalle sobre las características, los comportamientos y los pensamientos de quienes protagonizan los mismos.

Puede apreciarse que ésta investigación se fortaleció por el valor del tiempo presente durante el cual se desarrolló, la forma/modo como se asumió y lo subjetivo que prevaleció, de manera que el modelo tradicional como orden para la realización del trabajo fue objeto de la subversión de lo emergente de ésta vivencia. De tal manera que los Objetivos propuestos para alcanzar el propósito del estudio se presentaron como indica Viloria ${ }^{23}$.

\footnotetext{
22 Ibídem., p. 32.

${ }^{23}$ Ibídem., pp. 60-61.
}

Rev. hist. edu. latinoam. Vol. 15. Año 2010, pp. 299 - 322 


\section{Propósitos Pertinentes}

- Interpretar los procesos históricos que caracterizan el desarrollo de la Educación en Venezuela, luego de la muerte de Juan Vicente Gómez.

- Identificar las perspectivas para la construcción del futuro educativo, desde una nueva realidad de la Educación en Venezuela en el devenir de las transformaciones sociales, políticas y económicas ocurridas.

- Conocer e interpretar las vivencias y relatos de Gilberto Picón Medina, un testigo presencial del desarrollo de la Educación en Venezuela y las influencias de los factores políticos, económicos y sociales en dicho proceso.

La ruta sugerida por el cumplimiento de las tareas propuestas, nos conducirá hacia el propósito de envergadura que coronará el esfuerzo, el mismo se traduce en la construcción de la historia de vida de Gilberto Picón Medina, para desde ella poder apreciar cómo vivió sus tiempos y las experiencias vividas, de manera tal que nos permita una diferente visión sobre lo acontecido. Así, el norte de esta expedición se expresa en una pretensión, y es: La Pretensión General, esta comprender la historia de la Educación Venezolana luego de la muerte de Juan Vicente Gómez hasta el presente (1935-2006), desde las memorias, los relatos y la mirada de Gilberto Picón Medina. Un testigo presencial, y construir una semblanza con diferente óptica.

Ésta investigación profundizó sus esfuerzos por ratificar el valor de lo humano como elemento vital en su desarrollo, en virtud de esto Viloria ${ }^{24}$ señaló, La presencia del hombre en su accionar y pensar hace posible que el pasado, el presente y el futuro sean los espacios de tiempo, donde se concreta su accionar y pensar. La realidad de cada quien, hace posible que cada tiempo de presencia sea un momento concreto y en consecuencia al actuar ese momento es compartido con los otros y existe de esta manera un tiempo común que establece donde se desarrolla el todo social.

La indagación de los asuntos teóricos como soporte y acompañamiento de la vivencia, consideró de manera significativa la información de primera fuente como la suministrada por los informantes clave, desde donde se logró la sistematización necesaria para que lo teórico-epistemológico de la investigación presentara su rostro humano. En cuanto a la definición del Método que se administró para el desarrollo de la investigación, es necesario decir que ésta vivencia resultó un ejercicio inter y trans-disciplinar de Métodos. Se procuró, según escribe Viloria ${ }^{25}$ Construir la Historia de Vida de este venezolano (Gilberto Picón Medina) de

\footnotetext{
${ }^{24}$ Ibídem., p. 63.

25 Ibídem., pp. 40-41.
} 
reconocida trayectoria, desde su intimidad como persona, padre de familia, militante político y como educador -su vida en colectivo-, hará posible conocer un lado diferente de la historia de la educación venezolana, que enriquecerá la noción que sobre ella tenemos como producto de los registros que han utilizado los historiadores para presentar la historia del país y en particular la de la educación.

Ésta construcción necesitó practicar Métodos como las Historias Orales, la Entrevista en Profundidad, la Revisión de Documentos Personales y el Método Biográfico. Y como valor agregado, la conjugación de éstos Métodos fue posible gracias a la Narración. No sólo como una manera de instrumentalizar la comunicación, sino como indica Viloria ${ }^{26}$, se hizo Método porque, "Así podemos apreciar que los testigos, sus vidas, biografías, relatos y todo cuanto nos conecte con lo pasado vivido, contribuye a que logremos una mirada diferente de la historia. Y esa nueva mirada ha de socializarse a través de lo escrito, porque

..., las memorias y testimonios ofrecidos no significan rehacer cada evento tal cual ocurrió, sino que son producto de los relatos y recuerdos que se han de comunicar de manera oral y/o presentando evidencia no de los hechos como tal, sino de situaciones que nos aproximarán al mismo. ${ }^{27}$

Ésta investigación ofrece una visión de la movilidad de la Educación y la Escuela venezolana por un espacio superior a los setenta años, no arroja detalles extremos de todo lo ocurrido, pero sobre los asuntos que se trabajó y en los cuales los informantes clave fuero testigos si hay detalles significativos. Por tratarse de una Historia de Vida y el protagonista aún vive, resultaba una contradicción presentar conclusiones.

El cierre del trabajo se caracteriza por dejar abiertas las posibilidades de continuar en ésta indagación, por ello los hallazgos alcanzados son presentados de manera argumental y ofrecidos como provocaciones. Provocaciones porque son realidades que hemos asumido como verdades legítimas, y sobre ellas han sido pocas las cosas que hemos hecho por cambiarlas o transformarlas de manera contundente. Las Provocaciones presentadas son cuatro. La primera Provocación, "Un modelo educativo foráneo." Tiene que ver con el hecho que Venezuela no cuenta con un Diseño Curricular Autóctono. Los diversos diseños curriculares que se han administrado en Venezuela son de origen extranjero, desde los tiempos de la colonia hasta los tiempos actuales, los gobiernos de Venezuela siempre han recurrido a las ofertas extranjeras y no han procurado crear diseños que respondan a la realidad del País.

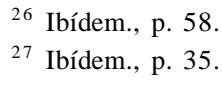


La segunda Provocación, se ofrece desde la expresión "La escuela nunca se interesó por lo que yo sabía." Venezuela como país, desde la llegada de los europeos, ha sufrido la imposición de normas, modelos y diseños políticos, sociales y de formación y los ha asumido en un escenario de cotidianidad que ha facilitado el desconocimiento de nuestros propios saberes y reduciéndola fortaleza de nuestra identidad. En el medio educativo, específicamente en el escolar esto se tradujo en una máxima. "A la Escuela se va a aprender", "se comienza a aprender desde cero", "lo nuevo está en la educación de la escuela",...Tanto que educarse era la vía para superar los estatus sociales, la profesionalización del colectivo orientaba en "buen sentido" del desarrollo social.

En tiempos recientes la identidad local, regional y nacional ha sido objeto de dedicación y esfuerzos desde las prácticas gubernamentales para reafirmarlas como valor social, político y de vida de la nación. Pero durante tiempos anteriores eran asuntos necesarios de no considerar porque limitaban el desarrollo educativo. Una vez que el niño o niña llegaba a la escuela, era considerado un ser que requería de lo que en la escuela se enseñaba, no se consideraba lo que del saber cotidiano o profano esa persona traía consigo, resultaba poco o nada necesario para su formación.

Hoy a pesar de los esfuerzos desde los gobiernos, continua presente la idea de que sólo lo nuevo de la educación escolar es lo que interesa y sobre lo que hay que trabajar. Sobre ello Viloria, ${ }^{28}$ refiere con nostalgia refiere (Gilberto Picón Medina) que al llegar a la ciudad de Mérida, su ruralidad quedó en las Montañas. Cuántos niños, niñas, mujeres y hombres lamentan que la escuela ignore sus capacidades como herramientas útiles para su formación como ciudadanos de hoy.

La tercera Provocación “Orden y Disciplina”, los argumentos que se ofrecen para ésta tercera provocación tienen que ver con hechos históricos ocurridos que demandan una especial atención. La frontera histórica que limita los siglos XIX y XX en Venezuela, está cargada de guerras federales y montoneras. Acontecimientos que facilitaron niveles de anarquía, desorden político, social e ingobernabilidad. Incubando El Caudillismo como ejercicio del liderazgo para controlar la realidad del país. Dice Viloria ${ }_{2}^{29}$ "Las montoneras, los coletazos de la Guerra Federal y el Liberalismo sumergieron al país en un atraso profundo. Donde el ejercicio del liderazgo respondía a una práctica del poder por abuso de la fuerza,..." Luego de la llegada de Cipriano Castro al

${ }^{28}$ Ibídem., p. 213.

Ibídem., p. 215 
poder, el control del poder político y gubernamental en Venezuela estuvo en manos de los andinos por más de cincuenta años.

Y durante este tiempo se produjo la creación e incremento de las Escuelas Normales en el país. Centros de formación de Maestros sobre lo que expresa Viloria. ${ }^{30}$ Como podemos ver el ejercicio del poder y la autoridad desde la actitud de los andinos resulta con características particulares, pero lo que interesa es preguntarnos hasta dónde este modelo de jefatura no se refleja en el rol y ejercicio de la autoridad desde el Maestro, que como se ha señalado las Escuelas Normales, donde se forman los docentes, incrementan su número de creación durante los gobiernos liderados por andinos y que, el perfil del diseño curricular para su formación responda a esta exigencia de gobierno. En otras palabras, hacer un Maestro a imagen y semejanza del Hombre andino que gobierna.

La cuarta Provocación "Gilberto Picón Medina, la Escuela y la Educación en Venezuela. Entre la Muerte de Juan Vicente Gómez y el Siglo XXI. Una Sinopsis.”, pretende ofrecer una visión histórica de la realidad del país, la movilidad de la escuela y la educación teniendo como eje gravitatorio la vida de Gilberto Picón Medina, de manera tal que su condición de testigo presencial de los hechos permita indagar a profundidad estos eventos y hechos.

Se diseñó una matriz a tres columnas donde se recogen las informaciones que pueden manejarse como registros y evidencias que invitan a sumergirse en ellas y lograr mayores referentes.

Una mirada a la Escuela y la Educación en Venezuela. Desde las vivencias y experiencias de Gilberto Picón Medina. Una vida académica ${ }^{31}$

\begin{tabular}{|c|c|c|}
\hline $\begin{array}{l}\text { Eventos Históricos } \\
\text { Ocurridos }\end{array}$ & $\begin{array}{c}\text { Gilberto Picón Medina, } \\
\text { Su vida }\end{array}$ & $\begin{array}{l}\text { La Escuela y la Educa- } \\
\text { ción en Venezuela }\end{array}$ \\
\hline $\begin{array}{l}\text { En ésta columna se ubican los } \\
\text { hechos históricos registrados } \\
\text { en el país, divididos en perío- } \\
\text { dos. La muerte de Juan Vicen- } \\
\text { te Gómez, Gobierno de Isaías } \\
\text { Medina Angarita, caída del } \\
\text { gobierno de Rómulo Gallegos } \\
\text { y dictadura de Marcos Pérez } \\
\text { J. y el período democrático. }\end{array}$ & $\begin{array}{l}\text { Relatos, narraciones, docu- } \\
\text { mentos personales e infor- } \\
\text { mantes clave que dan } \\
\text { cuenta de la vida de } \\
\text { Gilberto Picón Medina. }\end{array}$ & $\begin{array}{l}\text { Arqueología del movi- } \\
\text { miento de la educación ve- } \\
\text { nezolana. }\end{array}$ \\
\hline
\end{tabular}

30 Ibídem., p. 215.
${ }^{31}$ Ibídem., p. 218. 
Para culminar este aparte una última reflexión de Viloria ${ }^{32}$ Las virtudes y atributos que engalanan a la Escuela y la Educación, la ubican como una práctica ideológica que fortalece la convivencia democrática de las comunidades y pone en riesgo a los gobiernos que pretenden restringir este derecho, sin embargo estos últimos para perpetuarse en el poder hacen esfuerzos para transformarla y ponerla a sus servicios, pero ambas son por naturaleza contestatarias y auténticas. Al parecer la Escuela y la Educación, saben que su asunto es el crecimiento, desarrollo y evolución armónica de las sociedades.

\section{La Pedagogía Social en el escenario de la Educación Social. Un momento para múltiples miradas ${ }^{33}$}

Ésta investigación permitió evidenciar, desde su vivencia, lo valioso de admitir la emergencia de eventos que enriquecen los procesos de indagación. Ello gracias al enfoque desde el cual se atendió su desarrollo y realización, el fenomenológicointerpretativo. Lo que se propuso en ésta investigación trató de lograr una elaboración teórica y argumental, desde la cual se colocará el concepto de Pedagogía en discusión. Durante tiempos recientes se habla de Pedagogía Social con lo que se busca establecer una diferenciación con la Pedagogía Escolar. Pero resulta que la Pedagogía es una manera/forma de hacer posible las prácticas políticas para lograr la convivencia en colectivo. En Venezuela ésta práctica es la manera de desarrollar los procesos educativos, como apunta Viloria. $^{34}$

La vida en colectivo, a primera vista, es el quehacer cotidiano que desarrollamos desde que nacemos. En el grupo familiar donde llegamos al nacer somos recibidos, y desde ese momento comienza nuestro proceso de relación con otros. En el transcurrir del tiempo mientras vamos creciendo, aprendemos que formamos parte de grupos sociales; la familia, los vecinos, la comunidad.

Adicionalmente ese proceso de evolución y desarrollo del grupo social, tiene que ver con el cómo lo hace la sociedad, dónde lo desarrolla y con qué instrumentalización se acompaña en camino al éxito del esfuerzo empeñado. Sobre esto dice el citado autor, Las sociedades organizadas definen y precisan las razones que motorizan su movilidad y cambios en el proceso de su crecimiento como grupo, su desarrollo como comunidad y evolución como garantía de

\footnotetext{
${ }^{32}$ Ibídem., pp. 223-224.

${ }^{33}$ VILORIA ASENCIÓN, José (2009): La Pedagogía Social en el escenario de la Educación Social. Un momento para múltiples miradas. Informe Final del Proyecto de Investigación S1-07-002 UNESR-CDCHT. No publicado. Caracas, Venezuela.

${ }^{34}$ Ibídem., p. 5.
} 
prevalecer en el tiempo y el espacio. La Educación es uno de los elementos vitales para avanzar en esa motorización de las comunidades. Sea esta escolar o no, siempre está presente como factor determinante y evaluador de los cambios $\mathrm{y}$ transformaciones que se perciben en semejante dinámica. ${ }^{35}$

La Educación venezolana cuenta con un sinfín de héroes anónimos en el desarrollo de ésta práctica en el medio escolar, los Maestros y Maestras que a diario responsablemente asumen ésta titánica tarea. Pero además la Educación tiene junto a los Maestros y Maestras otros aleados que hacen posible el éxito de sus propósitos. La familia, las organizaciones sociales, la cultura y los deportes entre otros. En el desarrollo de ésta investigación se procuró trabajar sólo con los docentes, pero en el tránsito del devenir investigativo asistí como Ponente al I Seminario Iberoamericano de Cooperación en Gestión Deportiva (Barcelona, España Mayo 2008). Donde presenté un trabajo titulado "Pedagogía y Educación Social. Una Agenda para la Gestión Deportiva.” En dicho trabajo se ofreció “...una serie de reflexiones sobre el recorrido histórico de los eventos deportivos y olímpicos, en los cuales se pueda percibir que las actividades físicomotoras y los deportes configuran espacios para el desarrollo humano en lo social, educativo, cívico y político." ${ }^{36}$

Éste ejercicio permitió ampliar la visión sobre el asunto que estaba trabajando, lo emergente resultó nutritivo para la investigación. Seguidamente ubiqué un grupo de Maestras y Maestros egresados de Escuelas Normales, el Instituto de Mejoramiento Profesional del Magisterio y Ciclo Diversificado como Bachiller Docente. Adicionalmente trabajaron como Maestros de Aula, Director y Coordinador de Biblioteca. Todos tienen una conexión afectiva con el estado Trujillo. Nacieron allí o son descendientes directos de trujillanos (Blanca Zapata). Desde la administración de la Entrevista en Profundidad se pudo lograr que cada una y uno de ellos expresara desde sus vivencias y experiencia cómo desarrollaban la Educación y evidenciaron su sentido pedagógico en las mismas.

Blanca Zapata Maestra egresada como Bachiller Docente de la Gran Colombia Caracas, Venezuela, en entrevista con Viloria ${ }_{3}^{37}$ manifestó la necesidad del sentido vivo de la Educación, la Pedagogía debe ser dinámica y participativa. Cuenta ella, "Yo decía en los consejos de docentes, que si en el salón no hay movimiento, bulla entonces están muertos los alumnos. Si la dinámica de aprender demanda alteración de ciertos órdenes las estrategias del docente orientaran el

\footnotetext{
${ }^{35}$ Ibídem., p. 12

${ }^{36}$ Ibídem., p. 95

${ }^{37}$ Ibídem., p. 49.
}

Rev. hist. edu. latinoam. Vol. 15. Año 2010, pp. 299 - 322 
proceso." El Maestro Emiro Briceño, oriundo de Niquitao estado Trujillo, Venezuela. Obtuvo su título de Maestro en el Instituto de Mejoramiento Profesional del Magisterio (IMPM). La Pedagogía vivida por Emiro Briceño se centró en la persona humana, su amor, lo emotivo y lo colectivo de vivir junto y con el/los otros. En entrevista con Viloria, ${ }^{38}$ expresó, "Ellos siempre me manifiestan respeto, cariño, mucho cariño; porque en el proceso de formación trabajé con amor que se debía a ellos y le invocaba el momento propicio para darles la inquietud que uno tenía para su mejor preparación."

Josefa Camacho de Briceño, también nacida en Niquitao, expresó lo legítimo de lo humano como la razón que motoriza los esfuerzos por desarrollar una Educación con alto sentido humano, es decir, practicar una Pedagogía en y para la vida en colectivo. Durante la entrevista con Viloria, ${ }^{39}$ señaló; Me gustaba el trabajo con los niños por eso me fui a estudiar al Colegio Nuestra Señora de Fátima en Boconó, dirigido por Hermanas Dominicas. Donde se daba una educación maravillosa yo siempre creo que tuve suerte de estar en un Colegio donde la educación se daba más que todo en valores que en estudios. Es decir, primero formar a la persona porque cuando la persona se forma entonces asimila más lo teórico ó sea el estudio las materias.

María Elaide Briceño Pérez de Paredes, Trujillana y egresada del IMPM, contó durante la entrevista lo siguiente; A nosotros nos tocaba barrer la Escuela verdad, hacer los trabajos que correspondían a las Secretarias y a dar las Clases a los muchachos, y visitar a las familias, los hogares de los niños. Sobre todo eso porque no nos íbamos a quedar los sábados en la casa sin que hubiera una visita realizada. El sábado o dábamos clases medio día o visitar hogares. ${ }^{40}$

No sólo era el hecho o la responsabilidad de cumplir con un Programa Curricular y cubrir un determinado número de horas académicas, el asunto era el muchacho, su familia y la convivencia social. Adicionalmente entre los valores de convivencia "La Puntualidad" para ella es asunto de honor, "Nunca nadie jamás me dijo nada de mi puntualidad. Yo siempre procuraba estar un cuarto de hora antes de comenzar las clases, y cuando podía media hora antes." Silvia Aurora Delgado de Barreto, dice "...yo era una maestra de media arepa, ${ }^{41}$ con un sexto grado simple y llanamente, yo toda la vida he sido una mujer humilde una mujer

\footnotetext{
38 Ibídem., p. 63.

${ }^{39}$ Ibídem., p. 57.

${ }^{40}$ Ibídem., pp. 52-56.

${ }^{41}$ La expresión "media arepa", se entiende como algo incompleto o que faltó algo. La Maestra Silvia hizo referencia al hecho de que ella se inició como Educadora sin la Formación adecuada o requerida, pero manifiesta orgullo de la labor cumplida.
} 
pobre, pero sin embargo he sabido vivir." ${ }^{2}$ Ésta trujillana nacida en Burbusay, desde el inicio deja claro su valor por el trabajo como acto y ejercicio de formación. El empeño y formalidad del trabajo como práctica de la responsabilidad orientó su desempeño como Maestra Rural en el pueblo de Moskey, lugar ubicado en la sierra del estado Trujillo, próximo a la ciudad de Boconó.

Vivió con intensidad ser Maestra, al punto que se hizo parte de la familia de los muchachos y muchachas que fueron sus alumnos. Ella era parte de la cotidianidad de esas familias, donde evidenciaba el sentido de la horizontalidad como factor trascendente en acto de Educar desde la Escuela, la familia, la cocina, la misa de los domingos. No establecía diferencias entre los contextos que favorecieran la formación de niñas y niños.

Nos contó, ...iba de casa en casa, cosa que (los Maestros) no hacen hoy en día. Yo de casa en casa fuera sábado, fuera domingo o después que salía del trabajo..., yo llegaba a la casa de esta joven, pasaba para la cocina hola Maestra, hay caraotas, yo le contestaba no importa yo quiero caraota yo quiero comer caraota; hoy lo que hay es gallina yo quiero comer gallina de lo que hubiese yo comía..., me hacía familiar, entonces parte de Silvia era de esa gente y esa gente parte mía. ${ }^{43}$

Estas iniciativas no eran parte o producto de un currículo de formación, al parecer era una necesidad sentida y percibida por Silvia, y ella supo sacar provecho para que su vida como Maestra resulte satisfactoria e inolvidable para sus alumnos, las familias y por supuesto para ella.

José Viloria: Buenas tardes ¿Profesor?, ¿Maestro? ¿Cómo le digo?

César la Bastida: Maestro, ese es el mejor título que se puede ostentar, mi nombre es César La Bastida, José Viloria: Como lo conocen aquí, pero cuál es su nombre. César de la Bastida: César de la Bastida, es un apellido español. ${ }^{44}$

Así comenzó el encuentro sostenido con César de la Bastida, quien no se inmutó cuando la gente del pueblo de Burbusay modificó su apellido. Las Maestras y Maestros son seres humanos que viven en y desde las relaciones con los otros, también sufren, padecen y disfrutan al igual que los demás las cosas cotidianas de la vida. Pero al asumir la Educación como escenario de relaciones de un presente en procura de construir un futuro, inician una diferente forma y manera de asumir la vida.

\footnotetext{
${ }^{42}$ Ibídem., p. 71.

${ }^{43}$ Ibídem., p. 73.

${ }^{44}$ Ibídem., pp. 80-82.
}

Rev. hist. edu. latinoam. Vol. 15. Año 2010, pp. 299 - 322 
La identidad de los Maestros en su quehacer se enriquece de varios nutrientes, los muchachos, sus familias, la profesión y el sitio donde se desempeña. Para César la Bastida el primer impacto resultó ser Burbusay, y en sus palabras está la evidencia, "Y desde que vi a Burbusay desde la Mesa Redonda quedé enamorado. Me impactó, me fascinó el pueblo solamente al verlo desde la Mesa Redonda." Desde ese instante pareció entender que su trabajo no era sólo con los muchachos, sino con todos los habitantes del pueblo, hizo énfasis en la responsabilidad compartida con todos por el éxito de la Educación en todas sus dimensiones.

Relató esta anécdota que recoge estrategias que definitivamente no tiene desperdicios;

Las reuniones eran los primeros domingos de cada mes, como a los cinco meses recalqué "vamos a comenzar las reuniones a la hora", a pesar de que todavía no eran puntuales, yo procuraba agilizar las reuniones punto propuesto se incorporaba a la agenda y se trabajaba. En determinado mes, no recuerdo con precisión, comencé puntual. Las reuniones las hacíamos una vez que terminaba la misa de nueve o diez, es decir a las once y cuarto estaba pautada la reunión. Entonces comencé puntualmente, pero ya había referido que si estaban puntuales conocerían lo tratado en los puntos iníciales y si no estaban no se podía hacer nada y no podrían reclamar, entonces como le dije comencé a la hora y ese día agilice más, adrede, cuando estábamos tratando el último punto estaba llegando la mayoría de los representantes, y "Santa Pascua dijo un Cura", hasta el próximo mes. Pero al siguiente mes, es decir, en la próxima reunión todos estaban a la hora. ${ }^{45}$

Puede observarse que durante ésta investigación se logró una diversidad de conceptos sobre cómo cada uno de los informantes expresó lo que vivió, practicó y desarrolló como Pedagogía para dejar la huella de su esfuerzo en la relación con los otros. La Pedagogía en definitiva es una práctica política dirigida al fortalecimiento de lo individual del colectivo y lo colectivo de los individuos. Durante la última mitad del pasado siglo XX, las Maestras y los Maestros que sirvieron de testigos clave en ésta investigación así lo dejan ver.

\section{CONCLUSIÓN}

\section{Voces Anónimas e Interlocución. Dar la Palabra a la Educación}

La investigación en las Ciencias Sociales es una de esas áreas del saber,

\footnotetext{
45 Ibídem., p. 85.
} 
donde las diferencias enriquecen y confrontan ideas, posturas y pensamientos entorno a lo que en ellas y desde ellas se pretende conocer. El recorrido que ha cubierto el hombre en el desarrollo de la Investigación ha sido fructífero a pesar de las dificultades que ello implicó. Tal vez desde la invención de la rueda, pasando por el control del fuego como fenómeno físico las formas, maneras y modos como el hombre ha logrado descubrir sus potencialidades de las que dispone para relacionarse con su entorno, uno de los factores que ha resultado con mayor dificultad ha sido conocerse así mismo.

Conocerse como individualidad y colectivo, las tortuosas estrategias y acciones para entenderse con sus semejantes y cómo ha logrado los niveles de relación y configuración de vida colectiva, lo inquietan ${ }^{46}$. Aceptar y rechazar las diversidades y diferencias que lo caracterizan todavía son asunto de interés y estudios. Hoy tiempos de globalización, comunicación digitalizada, manejo de información inconmensurable, la confrontación entre el manejo y control de una verdad supuesta y lo relativo de las certezas, alimentan la Investigación en las Ciencias Sociales.

La humanidad está reclamando el protagonismo que le corresponde como actor principal del quehacer diario del hombre en el mundo. Por ello Sarlo ${ }^{47}$, dice, El pasado es siempre conflictivo. Aél se refiere, en competencia, la memoria y la historia, porque la historia no siempre puede creerle a la memoria, y la memoria desconfía de una reconstrucción que no ponga en su centro los derechos del recuerdo (derechos de vida, de justicia, de subjetividad)."

Pero nos encontramos que los datos, lo contable, lo medible, lo numérico que vigorizó lo pragmático de la revolución industrial y la producción en serie, se mantiene presente. Muy a pesar de que las manifestaciones sociales, políticas e investigativas han estado haciendo lo propio para el reconocimiento de la esencia humana en los logros modernos. Donde la actitud que caracteriza el tránsito hacia lo posmoderno, otorga una opción para satisfacer este reclamo.

Hoy resulta difícil de entender como se le pretende restar valor y legitimidad a lo subjetivo en el desarrollo de la Investigación en Ciencias Sociales. Esta disputa ha sido suficientemente discutida y confrontada, por ello en estas tres investigaciones se centró el esfuerzo en hacer la presentación de aspectos en

\footnotetext{
${ }^{46}$ Para profundizar estas ideas revisar: ARENDT, H. (1997): ¿Qué es la política?, Barcelona, España Ediciones Paidós Ibérica, S.A.; ARENDT, H. (2003): Responsabilidad y juicio, Barcelona España Editorial Paidós.

${ }^{47}$ SARLO, Beatriz. (2006): Tiempo Pasado. Cultura de la memoria y giro subjetivo. Una Discusión. México Siglo XXI Editores. S.A., p. 9.
} 
los que se muestran elementos relevantes para legitimar el valor de lo subjetivo en la Investigación en las Ciencias Sociales, caso especial la Educación. Maturana ${ }^{48}$ indica que, Los seres humanos no somos todo el tiempo sociales; lo somos sólo en la dinámica de las relaciones de aceptación mutua. Sin acciones de aceptación mutua no somos sociales. Sin embargo, en la biología humana lo social es tan fundamental que aparece a cada rato y por todas partes.

La diferencia del cómo actuamos -porque somos únicos- es lo que nos identifica en cuanto sujeto que vive en el mundo. Los comportamientos sociales son producto del encuentro de coincidencias de intereses y necesidades, pero las diferencias permanecen. Dan sentido a nuestra legítima identidad. La cual compartimos en el convivir con otros que validan nuestro estar entre ellos y construimos el nos-otros. Validar nuestra presencia e identidad, se fortalece en el encuentro con otros que a su vez son diferentes entre ellos y claro está a nosotros.

La relación entre los humanos es la base y fundamento de la existencia de la humanidad, la que comienza desde el desarrollo de un proceso de relaciones con el entorno, las mismas se inician desde las interacciones sensoriales, y se fortalece progresiva y paulatinamente mediante el contacto con los otros desde el desarrollo y puesta en práctica del lenguaje. Fenómeno que refleja la expresa inteligencia humana como construcción-creación de entenderse-comunicarse para consolidar lo colectivo desde su individualización. Validando lo que señala Savater, ${ }^{49}$ al precisar "No estamos determinados a vivir en ningún paisaje ni en ningún clima, pero sí a convivir con semejantes que nos enseñen y ayuden."

Lo que se ha presentado es producto del esfuerzo por lograr una diferente percepción de lo que en Venezuela es la Educación, quiénes son las Maestros, cómo la sociedad guarda responsabilidad en la formación académica o no del colectivo $^{50}$, la Pedagogía como lo multidimensional de una práctica que tiene por asunto común la Política de vivir juntos y que junto a Ortega, ${ }^{51}$ digamos que, “...

\footnotetext{
${ }^{48}$ MATURANA, Humberto. (1997): Emociones y lenguaje en educación y política, Santiago de Chile, Chile, DOLMEN Ediciones., p. 77.

${ }^{49}$ SAVATER, Fernando. (2003): El valor de elegir. Editorial Ariel. Editorial Planeta Colombia, S.A., p. 25.

${ }^{50}$ Para ampliar este tema revisar: BRAVO, Jáuregui, L. y otros. (2004): Elementos para la Comprensión del Sistema Escolar Venezolana, Caracas, Venezuela, Universidad Central de Venezuela, Ediciones de la Biblioteca; BRAVO, L. y UZCÁTEGUI, R. [DC]. (2004): Memoria Educativa Venezolana. Universidad Central de Venezuela. Caracas, Venezuela; PRIETO FIGUEROA, L. (1990): El estado y la educación en América Latina, Caracas, Venezuela, Monte Ávila Editores, p. 54.

${ }^{51}$ ORTEGA ESTEBAN, José. (2005): La educación a lo largo de la vida: la educación social, la educación escolar, la educación continua... todas son educaciones formales, en: Revista de Educación No 338. Disponible en: http://www.revistaeducacion.mec.es/ re338/re338_11.pdf. p. 172.
} 
José G. Viloria Asención

la educación debe entenderse, en cualquier caso, como un todo en el espacio y en el tiempo, en la vida de los individuos en comunidad".

\section{REFERENCIAS}

ARENDT, H. (1997): ¿Qué es la política? Ediciones Paidós Ibérica, S.A. Barcelona, España.

ARENDT, H. (2003): Responsabilidad y juicio, Barcelona España. Editorial Paidós.

BOLÍVAR, Domingo y Fernández. (2001): “La Investigación Biográfica Narrativa” en: Educación, Madrid, España, Editorial La Muralla, S.A.

BRAVO, Jáuregui, L. y otros. (2004): Elementos para la Comprensión del Sistema Escolar Venezolana, Caracas, Venezuela, Universidad Central de Venezuela, Ediciones de la Biblioteca.

BRAVO, L. y UZCÁTEGUI, R. [DC]. (2004): Memoria Educativa Venezolana, Caracas, Venezuela Universidad Central de Venezuela.

CONCILIO VÁTICANO II, (1965): Constituciones. Decretos. Declaraciones, España. Ediciones Paulinas.

CONFERENCIA GENERAL DEL EPISCOPADO LATINOAMERICANO. (1986): MEDELLÍN, Conclusiones. Colección iglesia en acción $N^{o} 1$. Lima. Perú, Ediciones Paulina.

CONSEJO GENERAL DE LA SOCIEDAD SALESIANA,(1990). XXIII CAPÍTULO GENERAL SALESIANO: Educar a los Jóvenes en la Fe. Madrid. Ediciones CCS.

CÓRDOVA, V. (1993). Historias de Vida. Una metodología alternativa para Ciencias Sociales. Caracas, Venezuela, Fondo Editorial Tropikos.

MATURANA, Humberto. (1997): Emociones y lenguaje en educación y política. Dolmen. Chile Ediciones Santiago de Chile.

PRIETO FIGUEROA, L. (1990): El estado y la educación en América Latina, Caracas, Venezuela Monte, Ávila Editores.

RICOUER, P. (1999): Historia y Narratividad, Barcelona, España Ediciones Paidós.

RICOUER, P. (2002): Del Texto a la Acción. Ensayos de Hermenéutica II, México, Editorial Fondo de Cultura Económica.

RICOUER, P. (2004): La Memoria, La Historia, El Olvido, Buenos Aires, Argentina, Editorial Fondo de Cultura Económica.

SARLO, Beatriz. (2006): Tiempo Pasado. Cultura de la memoria y giro subjetivo. Una Discusión, México, Siglo XXI Editores. S.A.

SAVATER, Fernando. (2003): El valor de elegir. Editorial Ariel, Editorial Planeta Colombia, S.A.

Rev. hist. edu. latinoam. Vol. 15. Año 2010, pp. 299 - 322 
VILORIA, José. (2002): Formación de Jóvenes Bajo el Carisma de los Salesianos. Un Estudio de Caso, desde un Enfoque Etnográfico. Trabajo de Grado de Maestría no publicado. Universidad Nacional Experimental Simón Rodríguez.

VILORIAA., José. (2007): La educación y la escuela en Venezuela a partir de la experiencia de Gilberto Picón Medina: Una Historia de Vida. Venezuela Fondo Editorial de la Universidad Pedagógica Experimental Libertador. FEDEUPEL.

VILORIA A., José. (2009): La Pedagogía Social en el escenario de la Educación Social. Un momento para múltiples miradas. Informe Final del PROYECTO DE INVESTIGACIÓN S1-07-002 UNESR-CDCHT. No publicado. Caracas, Venezuela.

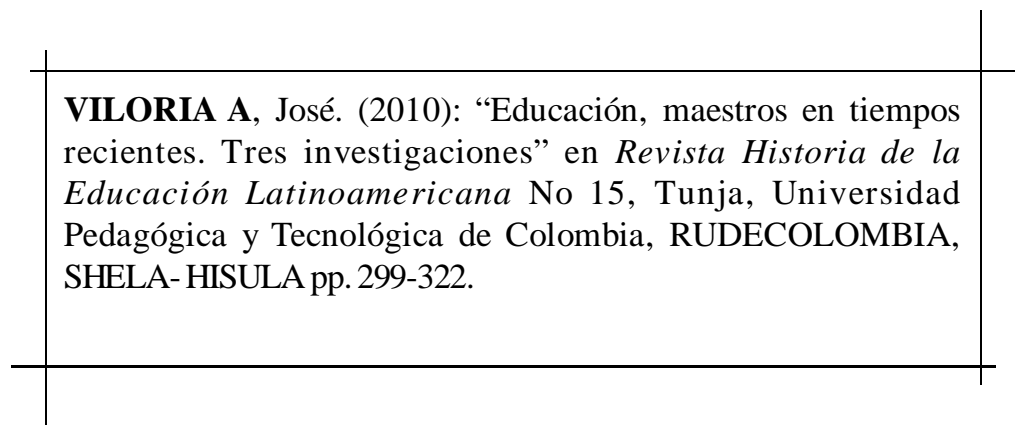

Rev. hist. edu. latinoam. Vol. 15. Año 2010, pp. 299 - 322 